\title{
Why not greater catch-up by Chinese firms? The impact of IPR, corporate governance and technology intensity on late-comer strategies
}

\author{
Yangao Xiao ${ }^{a}$, Andrew Tylecote ${ }^{b, *}$, Jiajia Liu $^{c}$ \\ a School of Management and Economics, University of Electronic Science E Technology of China, Chengdu 610054, PR China \\ ${ }^{\mathrm{b}}$ Management School, University of Sheffield, 9 Mappin St, Sheffield, S1 4DT, UK \\ ' Manchester Business School, University of Manchester, Booth Street West, Manchester M15 6PB, UK
}

\section{A R T I C L E I N F O}

\section{Article history:}

Received 8 April 2010

Received in revised form 5 November 2012

Accepted 17 November 2012

Available online $\mathrm{xxx}$

\section{Keywords:}

Late-comer firms

Technological catch-up

Intellectual property

Corporate governance

Chinese manufacturing

\begin{abstract}
A B S T R A C T
How can 'late-comer firms' (LCFs) in developing economies manage their development of technological capability, and within it their IP, strategically, in order to become fully competitive internationally? Under what conditions, external and internal, are they likely to succeed? This paper develops a theoretical framework for understanding LCFs' technology strategy and predicting its outcome, then applies it to the cases of three Chinese firms in sectors at different levels of technology intensity. This yields insights as to its limitations and further development. These help explain mainland China's very limited catch-up in high technology sectors - and to a lesser extent in medium-high technology. We show how our findings can be reconciled with the much greater success of Korean firms some 20 years earlier, if the effect of corporate governance differences is recognised.
\end{abstract}

(c) 2013 Published by Elsevier B.V.

\section{Introduction}

How should 'late-comer firms' (LCFs) in developing economies manage their development of technological capability strategically, in order to become fully competitive internationally? And why do they make the choices they do, among technology strategies? They need to transfer technology in some way from advanced 'foreign frontier firms' (FFFs); and they need to make some innovative effort themselves. Key issues are the manner of the transfer, and the timing of the effort. One widely held view has been that LCFs should focus initially on getting production capability through licensing or joint venture deals with FFFs, building independent technological capability by stages thereafter. This was the received wisdom in China at least during the 1990 s (e.g. Xia et al., 2002).

An alternative view is that the initial dependence which such strategies involve, has a way of becoming permanent, and that it may make for more success in the long run if technology transfer takes place from the beginning through 'imitative' strategies in which learning takes place more independently, with little help from the firm(s) being imitated, and perhaps even without their permission. We derive the dependent/imitative distinction from Freeman (1992), though our definitions are not quite the same as his; see next section and Liu and Tylecote (2009). An imitative strategy will typically 'unbundle' what in a dependent strategy would be a package or bundle of technologies all provided by the same Northern firm. Each element of the bundle will be sourced as convenient - by reverse engineering, or purchase from a domestic supplier, with licensing only where necessary; with core elements, where at all possible, developed using the firm's own design and engineering capability.

Lu and Feng (2004) found that within one sector of Chinese manufacturing, motor vehicles, the firms which followed dependent strategies had remained dependent; while two which had followed imitative strategies (Geely and Chery) had become rapidly stronger technologically and commercially (see also Liu and Tylecote, 2009). ${ }^{1}$ On the other hand Kim (1997) gives examples from Korea of rapid technological advance in close cooperation initially at least - with FFFs.

The obvious conclusion from this clash of cases is that the optimum choice of strategy - which at the outset might be reduced very simply to 'dependent versus imitative' - is likely to be contingent. Contingent on what? One plausible dimension of 'contingency' is sectoral technology level. It is likely a priori that imitation will be a great deal easier in a low-technology sector like clothing than in a high-tech sector like IT hardware or pharmaceuticals. Another dimension is the extent of the gap of technological capability with respect to the FFFs. Very probably when the gap is wide, an FFF will be quite relaxed about transferring technology to an LCF - and will

\footnotetext{
* Corresponding author. Tel.: +44 114222 3415; fax: +44 1142223348 .

E-mail address: a.tylecote@shef.ac.uk (A. Tylecote).
} 
thus co-operate to 'feed' a dependent strategy; as the gap begins to close, it will feel more threatened, and be less co-operative. A third dimension is the extent to which intellectual property is protected. The stronger are intellectual property rights (IPR) the more difficult it will be to carry through an imitative strategy, assuming that the FFFs involved do not wish to be imitated. We can see that with a narrow gap combined with strong IPR, FFFs may be unwilling to co-operate in a dependent strategy and rather well able to put a 'patent blockade' in the way of an imitative one.

Happily Freeman offers a third technology strategy, 'defensive', in which the firm develops its own more-or-less innovative technology, not really novel but distinct enough to give independent IP, and thus breaks through a 'patent blockade'. (There is also a fourth strategy, 'offensive', in which the new technology is genuinely novel.) Above a certain level of technological capability, then, the choice of strategy is three-way, including defensive. Or to put it another way, assuming the LCF is travelling along a trajectory of catch-up, it can pass from dependent to defensive, or from imitative to defensive.

There are two further contextual issues which are likely to be important. First, does the LCF operate in a protected market, of adequate size? Until the LCF has reached a more-or-less competitive level of production capability it is vulnerable to competition from any firm already at that level. Presumably an imitative strategy takes longer to achieve a given level of production capability than a dependent one in which an FFF is cooperating fully - cf. the Toyota/Nissan comparison in Cusumano (1985). If an LCF is able to operate in a market in which it is protected from the competition of FFFs, and of 'dependent' domestic firms with access to their technology, then an imitative strategy is more likely to be sustainable. Gao (2005) compares the strategies and performance of Chinese firms in two high-technology 'IT hardware' areas: telecommunications capital equipment and television. In both markets, Chinese firms were protected from the direct competition of FFFs. Gao found that in telecoms, strategic technology transfer restrictions made dependent strategies unattractive or infeasible, with the result that firms using imitative strategies (Huawei and ZTE) dominated the domestic market and then succeeded internationally with defensive strategies. ${ }^{2}$ In TV, many firms could and did use more or less dependent strategies, and Chinese firms remained uncompetitive internationally.

Second, corporate governance and finance will affect the choice of strategy, and its outcome. If imitative strategies take longer than dependent ones to reach a competitive level of production capability, and must be somehow sustained until they do, that is a challenge for corporate governance and finance. So is the provision of the R\&D resources needed for a defensive strategy.

The research discussed in this paper explores all the above issues, by way of three case histories tracing the evolution of three Chinese firms' technology strategies, with a particular focus on intellectual property. In two of the cases the period reviewed is some twenty years; the third case is shorter, about a decade, but the progress made was rapid. Accordingly all three firms covered a long distance in terms of technological progress. Moreover as Chinese economic policy changed, the context in which they evolved changed greatly, with respect in particular to IPR and to exposure to competition from FFFs. The three firms belong respectively to low-technology, medium-high-technology, and high-technology industries: viscose spinning, heavy steel plant, and TV/consumer electronics. They are all state-owned enterprises, and as such are typical of most of the firms which dominate the 'high ground' of

\footnotetext{
${ }^{2}$ Huawei were also ingenious in catering specifically for the very large rural market, which had requirements quite different from those for which foreign technology was designed (Xue and Liang, 2010).
}

Chinese industry. Section 2 reviews the literature relating to LCF technology strategy, and to its context: it ends by developing a number of propositions about conditions for success. Section 3 presents the cases, setting out the trajectories followed and showing how strategy evolved and - more arguably - why. Section 4 discusses what we have learned from these cases, and how they can be reconciled with the case histories of other LCFs in China and elsewhere. Section 5 concludes.

\section{Technology strategy for late-comer firms and the role of intellectual property}

\subsection{Technology catch-up: the key strategic choices}

A late-comer firm (LCF) is a late entrant to an industry, initially lacking technology and market access, focused on catch-up as its primary goal, and with few competitive advantages besides low costs in its industry of choice (Mathews, 2002). Clearly this describes the typical situation of the more ambitious firms in developing countries. What they are catching up in is, centrally, technological capabilities (TCs): the ability to use technological knowledge efficiently to assimilate, use, adapt and change existing technologies; and to create new technologies, developing new products and processes. TCs are the major determinant of industrial competitiveness (OECD, 1996; Schacht, 1997; Kim, 1997). We distinguish between static TC - the ability to use specific existing technologies for production at a point in time - and dynamic TC the rest of the capabilities set out above (Cai and Tylecote, 2008). This distinction gives us a way (Table 1 ) of classifying and evaluating Freeman's (1992) four technology strategies - dependent, imitative, defensive and offensive. ${ }^{3}$

We focus first on the two strategies between which the LCF has to choose initially: imitative and dependent. The 'imitative' firm is content, or obliged, for a time to follow behind the leaders in established technologies, possibly a long way behind. So is the dependent firm: the difference between the two strategies is in the relationship with foreign 'frontier' firms (FFFs). Both strategies may involve taking licenses from these firms, as indeed may defensive or even offensive strategies. But the imitative firm is seeking, or is obliged, to minimise its dependence, so that it will 'unbundle' the technology to be acquired, and do as much as possible for itself (see Section 1).

A dependent strategy, on the other hand, will typically involve buying, or rather renting, a bundle or package of technologies from one FFF - the classic case is buying a 'turnkey' plant. In a developing economy it may well involve a joint venture in which the foreign partner provides the technology, including training, and the domestic firm provides land, labour, contacts, domestic market access, and perhaps finance as in the case of Shanghai Automotive in Liu and Tylecote (2009). ${ }^{4}$ If the dependent firm is able and willing to spend enough money, and if its bargaining position for example in terms of market access - is strong, it may be able to acquire rather advanced product and process technologies. Its static capability would then be quite high. Its dynamic capability is on the other hand very low, because it need not do, and does not do, any of these things for itself. The strategy followed by the dominant 'insider' - state-favoured - firms in China during the 1990s was very much a dependent one (Liu and Tylecote, 2009). It might be clearer to say, the implied strategy these firms followed was

\footnotetext{
${ }^{3}$ Freeman also defines 'traditional' and 'opportunistic' technology strategies, but they do not concern us here.

${ }^{4}$ In our definition of dependent and imitative technology strategies we are departing somewhat from Freeman, who made 'dependent' a more limited category, in which the dependence was not merely technological, but total.
} 
Table 1

Technology strategy and capability matrix.

\begin{tabular}{|c|c|c|c|c|}
\hline & Dependent strategy & Imitative strategy & Defensive strategy & Offensive strategy \\
\hline $\begin{array}{l}\text { Nature of technology } \\
\text { strategy }\end{array}$ & $\begin{array}{l}\text { Passive - typically buy/rent a } \\
\text { bundle of technologies from } \\
\text { single provider }\end{array}$ & $\begin{array}{l}\text { Reactive - minimise } \\
\text { dependence, by unbundling } \\
\text { and reverse engineering }\end{array}$ & $\begin{array}{l}\text { Active - lead in engineering, } \\
\text { product design, or process } \\
\text { innovation; strong R\&D }\end{array}$ & $\begin{array}{l}\text { Proactive - be leaders in new } \\
\text { products, thro' own R\&D } \\
\text { and/or links with science base }\end{array}$ \\
\hline $\begin{array}{l}\text { Potential for enhancing } \\
\text { static capability }\end{array}$ & $\begin{array}{l}\text { Limited by finance and FFF } \\
\text { co-operation }\end{array}$ & Slow to achieve; limited by IPR & High & High \\
\hline $\begin{array}{l}\text { Potential for learning } \\
\text { and requirement for } \\
\text { dynamic capability }\end{array}$ & Low; low & High; medium & High; high & Very high; very high \\
\hline
\end{tabular}

Source: Authors' own composition inspired by Freeman (1992).

dependent. Continued dependence was not their avowed goal, or even, we suppose, their intention; it was simply the consequence of their actions.

Any firm following a defensive strategy is seeking to develop genuinely new technology, albeit only incrementally so; and it will use R\&D to do it, and patents, usually, to protect it. It is defending its freedom to operate independently in the industry, primarily from firms following an offensive strategy, who from time to time make breakthrough innovations. The LCF will presumably move to a defensive strategy once it has followed an imitative or dependent one as far as convenient - and is meeting increasing FFF resistance. Which is the better preparation for this move? This is perhaps the key question in catch-up, and the answer to it follows from our comparison above. The 'reactive' stance of imitation is better for developing dynamic technological capability, and thus for successful defensive strategy, than the 'passive' stance of dependence, however impressive the latter's results may be in terms of static capability, shiny new products and factories (see also Liu and Tylecote, 2009).

\subsection{The role of intellectual property within catch-up strategy}

Competitive advantage flows from the creation, ownership, protection and use of difficult-to-imitate knowledge assets (Teece, 1998) - from intellectual capital. Intellectual capital includes the skills, abilities, knowledge and know-how of a company's individual employees; a subset of this are intellectual assets, codified and defined knowledge; and the subset of these which are legally protected, is intellectual property (IP): the general rights that encompass patents, copyrights, designs and trademarks, as well as a host of related rights (Comish, 1996; Bently and Sherman, 2004).

On the face of it, while facilitating the transfer of static capabilities, by protecting an FFF licensor, intellectual property rights (IPR) make catch-up considerably harder. They may mean that an LCF which is (or could soon become) perfectly capable of producing product $\mathrm{X}$ with process $\mathrm{Y}$, at acceptable levels of quality and efficiency, is not allowed to do so: $\mathrm{X}$ and/or $\mathrm{Y}$ are protected by patents held by frontier firms. Alternatively it is allowed, but only on payment of royalties which remove the profits that it would otherwise invest in improving its capabilities. These go instead to the FFFs, which they may re-invest to maintain their lead.

The obstacles which IPR presents to catch-up vary by sector. They are small in sectors like steel or textiles, where the technology is mostly embodied in the equipment used, and patented by the equipment suppliers. LCFs can use the technology by buying the equipment on the same terms as any other firm (Odagiri et al., 2010b). This reflects the importance of vertical disintegration or specialisation: firms which make steel plant do not, generally, make steel and thus have no interest in obstructing catch-up by firms which do. Some cases of catch-up have owed much to 'elective' vertical specialisation. The US firm Qualcomm chose not to manufacture the hardware for a new mobile telecoms standard which it controlled, giving an opening downstream for Samsung and other Korean firms (Lee and Lim, 2001). Integrated circuit manufacturers chose to contract out their manufacturing, allowing Taiwan Semi-conductor Manufacturing Company (TSMC) into IC fabrication (Wu et al., 2010). Neither of these cases matches the smooth catch-up possible in steel and textiles: the Korean and Taiwanese entrants into these high-technology sectors still had a great deal to do, including expensive $R \& D$, in order to master the technologies in the sub-sectors that they were focusing on.

Another sectoral variation is between 'discrete' and 'complex' products - the latter being mostly assembled, as in motor vehicles and ICT hardware (Odagiri et al., 2010b). 'Complex' products have many components and elements, each likely to be patent-protected - together forming a 'technological blockade'. Rarely will a single firm have all the relevant patents. But the larger one's share in the total, the better one's position in negotiation - for cross-licensing (Motohashi, 2008). LCFs need at least enough patents to get to the table - a formidable undertaking. Existing players need not admit another unless it has 'blocking' patents on some valuable novelty that they cannot quickly invent round.

Perhaps the most important distinction, however, is by technological level, which by the OECD definition goes by R\&D intensity. High-technology sectors can be assumed to be advancing faster than medium-tech, medium-tech faster than low-tech. Compare, then, a high-tech product $X$ with a medium-tech product $Y$, equally complex. Fewer of the patents relating to $X$ will have expired. Among those not yet expired, more of Y's will be 'old' ones, for which there has been ample time for inventing round - so the patent-holders will be in a weaker bargaining position. Overall, the entry barrier posed by intellectual property rights in the mediumtech sector will be lower.

\subsection{The macro context of technology strategy: tariffs and FDI}

With inferior technological capability, LCFs cannot produce and sell in competition with advanced firms ${ }^{5}$; if they do not produce and sell, they do not learn by doing, a key route to improved TC. Import tariffs offer a way out of this bind - a protected home market in which LCFs may successfully produce and sell in spite of higher costs and lower quality. If there are also tight controls over foreign direct investment (FDI), the market is fully protected from FFFs. In this situation the LCF will more easily obtain licenses, because FFFs will have no other route to get profit from the protected market. Post-war Japan, till 1980, fitted this description, and so did 'reforming' China during the 1980s. However, Chinese tariffs started to fall during the 1990s, and by 2005, when its entry to the WTO was complete, China's gross average tariff level was about $5 \%$ - zero on some ICT imports (Walmsley et al., 2006). As of 2000, China's accumulated stock of FDI was $32.3 \%$ of GDP and rising rapidly due to

\footnotetext{
5 To be precise, they might, with inferior TC but much lower labour costs, produce for a price-sensitive segment of the market, as Chery did in its early development (Liu and Tylecote, 2009).
} 
the terms of WTO entry (Odagiri et al., 2010a, T4.4); though most of this was joint ventures with domestic state-owned firms. The corresponding figure for Japan is $1.1 \%$, and for Korea $13.7 \%$. The China-Korea difference is the more significant if we consider that the bulk of the FDI into Korea had come after 1985 (Lee, 2005), by which time the R\&D share in GDP was $1.4 \%$ and rising rapidly (Lee and Kim, 2010), showing a switch to defensive strategy. This ratio of R\&D to GDP was only reached in China in 2005 (Xue and Liang, 2010).

\subsection{The micro context of technology strategy: corporate governance and finance}

In high-technology sectors, the frontier is likely to be not only distant but advancing rapidly. To achieve catch-up there, and to a proportionately lesser extent in lower-tech sectors, the LCF must incur major effort and expense over a long period to develop capabilities, including intellectual property, which it will achieve and profit from only in the distant future - deploying patient capital (Sirmon and Hitt, 2003). Its ability and willingness to do this must depend on finance and on corporate governance: that is, the location of power and control over the firm, including the aims of those in control. We borrow from Liu and Tylecote's (2009) framework of analysis for Chinese corporate governance - and by extension the corporate governance of late-comer firms in general. They argue that an imitative technology strategy, using unbundling, poses two challenges to corporate governance: first, that the many, mostly small, inputs of effort and money required have low visibility to anyone not closely involved in the firm; second, they demand a high level of commitment and initiative from employees. Those in control of the firm therefore need high engagement with management, to appreciate low-visibility inputs and thus support a strategy which will not pay off quickly; and employees need to be, or feel, included if they are to show the necessary commitment and initiative to master all the diverse processes and product components involved. Absent such engagement and inclusion, a dependent, high-bundling strategy, will be highly attractive, since what is being bought or rented is highly visible, the FFF providing it takes responsibility for the quality of each element and their overall integration, and a pay-off should come quickly, in market share and profit. But good access to funds may be required, since the FFF can charge a high price.

The extent of shareholder engagement and employee inclusion are thus key features of LCF governance, particularly in early catchup, when the choice of strategy resolves, simplifying, to imitative versus dependent. Another important feature of governance is the industrial expertise of those in control, and providing finance. In early catch-up, and relatively low-technology industries - which are almost by definition not changing fast - the pathway that LCFs should follow will be relatively obvious. The closer to the frontier, and the faster it advances, the more difficult it is for LCFs to work out which path to follow - and the more they will need to use their own $R \& D$ to catch up. At later stages the choice is not between imitative and dependent strategy but among alternative defensive strategies - which technological option to choose. Those who choose, and those who monitor and finance them, need to have correspondingly high industrial expertise. One basis for engaged and expert governance may be that top managers have large shareholdings or some equivalent source of power (Liu and Tylecote, 2009).

\subsection{The IPR context in China}

Like all other firms, LCFs in developing countries can begin by discovering competitors' technology development and their technological innovation path through published patent information - particularly from the U.S. Patents and Trademark Office
(USPTO) and the European Patent Office (EPO). They may then find that a leader has not troubled to apply for a patent in their country. That will give them freedom to produce at home, as long as they do not attempt to sell where there is patent protection of the product. If they 'invent round' leaders' patents, and apply for a patent at home, they will find the examiners more inclined to concede novelty, than those of major developed countries - where the leader is, moreover, more likely to challenge the new patent.

So far, so general; but China does have specificities. Patent laws of some kind date back there to the late 19th century, but only in 1984 did China sign the Paris Convention on the Protection of Industrial Property of 1883 and adopt modern patent laws. In 1992 these were broadly aligned with international standards (Xue and Liang, 2010). With WTO entry, international norms were fully accepted from 2001, as set out in the international TRIPS agreement. By then patent law was being implemented seriously (Fai, 2005). Perhaps the most significant specificity is that SIPO (State Intellectual Property Office of China) is unusually demanding in the amount of detail required in the application, on how the invention works. The more detail is given, the more help is given to any prospective 'inventorround' (Neobard, 2009). So FFFs may be copied if they do not patent in China, and invented round if they do. Regional variations are also noteworthy: in the coastal provinces the courts are relatively impartial between different categories of plaintiff and defendant; in the inland provinces, where our firms are located, they favour domestic state-owned enterprises (Neobard, 2009).

\subsection{Propositions which follow from the above discussion}

P1. Catch-up for LCFs is easier, the lower the level of technology intensity of the sector, internationally. The lower the technological level of a sector, the greater the relative importance of domestic rivals. A developed IPR system gives more incentive and protection for ambitious catch-up strategy with respect to domestic rivals. On the other hand it makes it easier for Northern 'frontier' firms to defend their advantage against a late-comer firm. The IPR system(s) which are relevant in the latter case are however at least as much those in the North as those in the late-comer firm's own economy, since it will wish to sell abroad as well as at home. 'Inventing round' FFFs' patents to the point of breaking a patent blockade, is harder, the higher the technological level.

Therefore the development of the Chinese IPR system favoured technological innovation in lower-tech sectors, but not necessarily in higher-tech.

P2a. In earlier catch-up, the choice is broadly between imitative and dependent strategies. Imitative strategies are more effective than dependent ones in developing dynamic technological capability; but less immediately effective in increasing static TC. A large home market, protected by tariffs and controls on FDI, gives increased leverage in securing licenses from frontier firms. This may allow dependent strategies to be highly successful in rapidly improving static technological capability. If dependent strategies are indeed followed by major LCFs, this will weaken the market position of others following imitative strategies, and thus their ability to make these strategies succeed.

P2b. In later catch-up, FFFs become less and less willing to co-operate to transfer technology, and thus to facilitate dependent strategies, since LCFs might then become direct competitors on world markets, particular Southern ones. Imitative strategies also become more difficult, because of stronger patent protection of the frontier technologies to be imitated, reduced co-operation, as argued above, and greater technical difficulty in reverse engineering. Further catch-up therefore requires a switch to defensive, perhaps even offensive technology strategy. The greater LCFs' dynamic TC, the more likely they are to succeed there. 
P3. Corporate governance and finance affect the choice of, and success in, different types of technology strategy. Imitative strategies are more likely to be chosen, and successful, where governance is engaged and inclusive. Dependent strategies are more likely to be chosen where governance is disengaged and non-inclusive; and to be successful, where finance is plentiful and cheap.

Defensive and offensive strategies are more likely to be successful where finance is plentiful, and cheap, and where finance and governance display strong industrial expertise - particularly in higher-tech sectors (Fig. 1).

\section{The case studies}

This section sets out three case histories of technology strategy and intellectual property management in Chinese firms. In organisational research, the case study method is of course frequently adopted, and its particular values are well understood (Eisenhardt, 1989; Yin, 2003). It is ideally suited to answering 'how?' questions (Yin, 2008), so long as there is breadth of access and richness of data, which we had in all three firms, and a long temporal sweep in two firms we could look back over 20 years.

Case One is in a low-technology sector, textiles, more precisely viscose spinning - Yibin Grace Group Co. Ltd - 'Grace'. Case Two is in a medium-high-tech sector, heavy machinery, steel plant - China National Erzhong Group Co. - 'CNEGC'. Case Three is in a high-tech sector, TV/consumer electronics - Changhong Electronics Group Corporation - 'Changhong'. One common feature is that they are all located in Sichuan province, Western China: that is, inland and far from the most dynamic coastal regions. In explaining differences among them we can thus discount locational factors, though these may have to be taken into account where any similarities appear.

Table 4 summarises their profiles.

\subsection{Research methods}

\subsubsection{Data collection}

The method adopted in data collection was essentially of that of a participant-observer (Burgess, 1984), with many complementary sources of evidence, including questionnaire, interviews, archives and statistics:

1. Between July and December 2006, a structured questionnaire survey was posted to 100 manufacturing enterprises in Sichuan province, to be filled out by IP management or R\&D personnel. The 26 valid responses provided an initial understanding of the firms' general technological strategy and IP management. Three firms were then selected and approached for in-depth case study. The selection was based on three criteria: each of the firms was from a different technology level, low, medium-high and high-tech; each was highly active in technological development, as measured by R\&D intensity and patenting (Table 4); one of the authors has had a long-standing relationship with all three firms as an IP strategy consultant since the late 1990s, whereby unique access was granted for intimate participant observation (Burgess, 1984).

2. 17 semi-structured interviews were initially conducted by one of the authors from September 2007 to January 2008 in the 3 firms. Interviews were held individually and each lasted around $2 \mathrm{~h}$ (Table 2). We followed a 'cascade' interview technique: working down from General Managers, to Deputy General Managers, then to directors of technology centres, and to directors of IP management offices and finally directors of marketing departments. During the 6 site visits (see below), additional open-ended conversations were also conducted with engineers and workers to contextualise and verify the formal interviews. This interview sequence helped to generate holistic maps of the cases
Table 2

Interviews conducted at each firm.

\begin{tabular}{|c|c|c|}
\hline Firm & Department & Job titles of persons interviewed \\
\hline \multirow[t]{5}{*}{ Grace } & Top management & General manager \\
\hline & & Vice general manager \\
\hline & Technological Centre & Director ${ }^{\mathrm{a}}$ \\
\hline & IP Office & Director \\
\hline & Marketing Department & Deputy director \\
\hline \multirow[t]{5}{*}{ CNEGC } & Top management & General manager \\
\hline & & Vice general manager \\
\hline & Technological Centre & Director ${ }^{\mathrm{a}}$ \\
\hline & IP Office & Director $^{\mathrm{a}}$ \\
\hline & Marketing Department & Director \\
\hline \multirow[t]{6}{*}{ Changhong } & Top management & $\begin{array}{l}\text { Chairman of the Board } \\
\text { Vice general manager }\end{array}$ \\
\hline & Technological Centre & Programme general supervisor \\
\hline & IP Office & Director $^{\mathrm{a}}$ \\
\hline & & Employee $^{\mathrm{a}, \mathrm{b}}$ \\
\hline & PDP (Plasma) division & IP manager of Technology Department ${ }^{\mathrm{a}}$ \\
\hline & Marketing Department & Senior member of staffa,b \\
\hline
\end{tabular}

a Persons interviewed again through telephone calls between 2010 and 2011.

b Persons interviewed again through emails between 2010 and 2011.

in a limited time period. Interviews were carried out in Chinese and recorded by hand-written notes during the interview. ${ }^{6}$ In the interviews adjusted sets of questions were put to informants according to their operational roles; in particular, special discussions were held during the interviews with directors of technology centres and IP offices, to collect detailed data about the technological development and IP strategy in the firms. After initial data analysis, another 9 semi-structured interviews - 7 through telephone, 2 through emails - were conducted between December 2010 and November 2011 to update, verify original data, and to collect additional information.

3. Internal and external archival records. Published statistical data on official websites (SIPO of China, USPTO and EPO, OECD, etc.) were used for information on technology development and patent applications in different industrial technologies. In addition, unless otherwise stated, firm level data in this paper were collected from the firms, or calculated from data supplied from their internal statistics and archives. Dates of data are between 1990 and 2011.

4. Site observations. Between September 2007 and February 2008, one of the authors visited the technology centres of the three firms, and at least one manufacturing plant in each: a viscose fibre plant in Grace, a heavy machinery plant and foundry plant in CNEGC, a PDP plant in Changhong.

5. Other published sources. Case Three in particular draws substantially on the rich material in Xie and Wu (2003).

6. Personal communications with two leading scholars in the relevant fields in China.

\subsubsection{Data analysis}

To minimise biases arising from participant observation (Becker, 1958), all of the primary data was collected by the first author and secondary data by the third author, while the second author stayed out of the field altogether and played the role of 'devil's advocate'. The rationale is that he then would "...not become immersed in case details and may bring a very different and possibly more objective eye to the evidence" (Eisenhardt, 1989, p. 538). This tactic was particularly effective during the process of iteration (see below).

During the initial data analysis, to establish deep understanding of each case, we coupled narrative description with extensive use of

\footnotetext{
${ }^{6}$ Tape recording is very difficult in Chinese culture (Cooke, 2002). Interviewees were asked if they would accept it; however all were reluctant.
} 


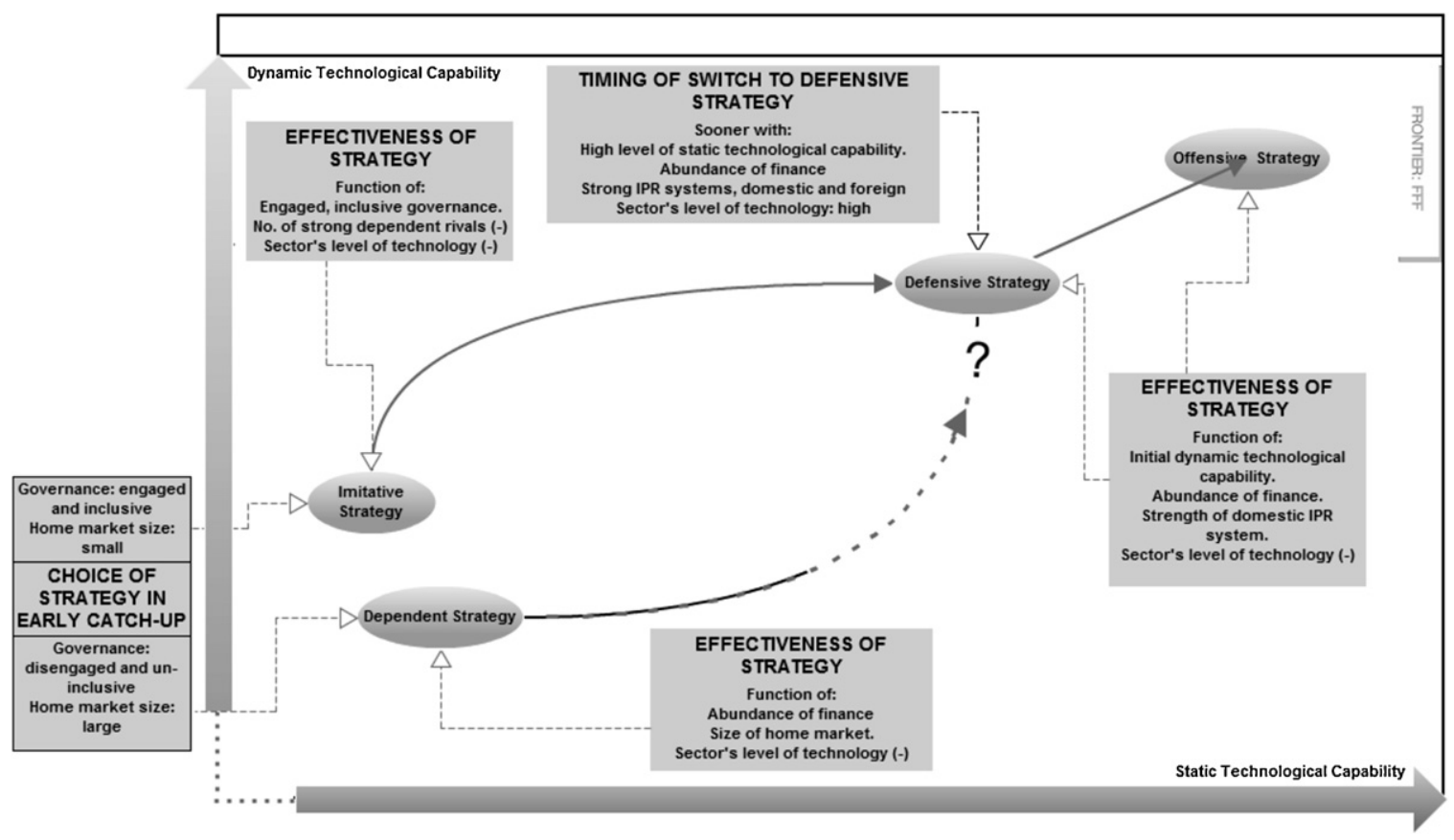

Fig. 1. Paths of catch-up: choice and effectiveness.

Table 3

China's performance in the three case sectors, in international perspective.

\begin{tabular}{|c|c|c|c|c|c|c|}
\hline $\begin{array}{l}\text { Technology category } \\
\text { (patent data) }\end{array}$ & $\begin{array}{l}\text { China's absolute } \\
\text { number of patents in } \\
\text { the class at USPTO }\end{array}$ & $\begin{array}{l}\text { China's share of all } \\
\text { non-US countries' } \\
\text { total in the class }\end{array}$ & $\begin{array}{l}\text { Revealed technological } \\
\text { advantage (RTA) }\end{array}$ & $\begin{array}{l}\text { Chinese R\&D intensity } \\
\text { in the sector }\end{array}$ & $\begin{array}{l}\text { US R\&D intensity in } \\
\text { the sector }\end{array}$ & OECD sector ( $R \& D$ data) \\
\hline $\begin{array}{l}\text { Textiles: spinning, } \\
\text { twisting, and twining }\end{array}$ & 3 & $1.41 \%$ & 2.14 & $0.36 \%(2010)$ & $0.59 \%(2002-2008)$ & $\begin{array}{l}\text { C17T19 Textiles, textile } \\
\text { products, leather and } \\
\text { footwear }\end{array}$ \\
\hline Metal working & 40 & $1.23 \%$ & 0.99 & $0.42 \%(2010)$ & $2.4 \%(2002-2008)$ & $\begin{array}{l}\text { C29 Machinery and } \\
\text { equipment, n.e.s. }\end{array}$ \\
\hline $\begin{array}{l}\text { Television and } \\
\text { television signal } \\
\text { processing }\end{array}$ & 18 & $0.29 \%$ & 0.32 & $1.36 \%(2010)$ & $14.7 \%(2002-2008)$ & $\begin{array}{l}\text { C32 Radio, TV, } \\
\text { communication } \\
\text { equipment }\end{array}$ \\
\hline
\end{tabular}

Source: Authors' calculations based on USPTO statistics, URL: http://www.uspto.gov/web/offices/ac/ido/oeip/taf/reports.htm.

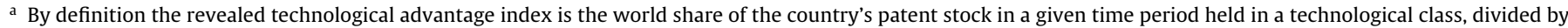

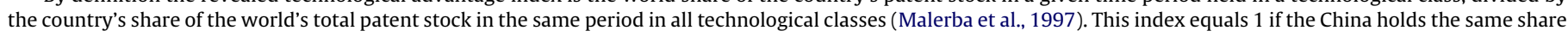
of worldwide patents in a given technology as overall, and $<(>) 1$ if there is a relative weakness (strength).

Calculations are based on Utility Patents (patents for inventions) granted, 5-year total of 2004-2008.

longitudinal graphs tracking firm details, such as technological and IP strategy, levels of dynamic capability, corporate governance and finance, general circumstances. We also used tabular displays about each case to identify comparable patterns. Explanations about the cases were then built through iteration (Yin, 2003); each case being set against the propositions in sequence, followed by cross-case comparison, to identify similarities and differences in the evolution of variables mentioned above. This process was facilitated by the devil's advocate in discussions among the authors, in which rival explanations were offered to clarify, confirm and test the initial propositions (Tables 3 and 4).

\footnotetext{
21 Since disaggregated data by sector or technology class is not available at SIPO, we used data from USPTO, which records China's patenting activity between 2004 and 2008. We have chosen the patent classes that we judge best matched to the areas of activity of the three firms. The data includes Hong Kong (a 'base of convenience' for many firms really based on the mainland).

${ }^{22}$ Local Government:(58.38\%); Provincial Government: (38.86\%) (2009).

23 CNEGC Group: (48.86\%); 2 state asset management companies: $(47.82 \%$ and $3.32 \%)(2007)$.

${ }^{24}$ Changhong Group: (29.83\%); the rest dispersed among state-owned institutional investors (2011).
}

\section{2. '2S' in Grace: improving mature technology to survive}

Grace is located in Yibin city of Sichuan province. It is a stateowned enterprise jointly owned by city (59\%) and provincial (39\%) government, and has grown out of a small chemical fibre factory founded in 1984. In 1997 Grace was on the edge of bankruptcy with 3000 employees and a production of 21,000 tonnes. An exceptional manager was needed, to save it, and the city government sought one among senior employees in the local firms it controlled. It found Feng Tao, who at the age of 30 was already sales director of the local paper mill - paper-making involving technology not very different from viscose. He was made CEO of Grace on the understanding that if Grace failed he would not be blamed; if it succeeded he would be generously rewarded - the informal Chinese SOE equivalent of stock options. ${ }^{7}$ By 2006 Grace had 12,000 employees, and was the biggest manufacturer of viscose fibre in the world, with a domestic market share of $33 \%$, and a global market share of $17 \%$.

\footnotetext{
${ }^{7}$ A not uncommon way of incentivising top managers of Chinese SOEs (Liu and Tylecote, 2009).
} 
We may note one key factor in this extraordinary turnaround. Any private firm in the very difficult financial and market situation faced by Grace in 1997 might have felt the need for innovation, but would have lacked the resources. Grace did not lack resources to deploy for innovation, as long as those resources were employees, because being an inland state-owned firm it was not allowed to fire redundant employees. ${ }^{8}$ It would even be under pressure to take on new R\&D employees, released from local R\&D institutes.

It is the technological innovation of " $2 S$ " that revived Grace. " $2 S$ " is a process innovation which our informants described as an A-bomb in the textile industry. By using a relatively simple technology, it advances from the traditional, 'semi-continuous' spinning technology of the past century in the viscose and other chemical fibre industry. (Advanced countries have for decades used a 'continuous' spinning technology, which is capital-intensive and accordingly is not optimal in developing economies with low-cost labour.) The typical methods to raise output of semi-continuous spinning machines are to lengthen the spinner or to speed up spinning. But " $2 S$ " does it differently: it produces two yarns at the same time. It is a technological improvement based on the existing technologies and production equipments - no coincidence, since only on this basis did Grace have the resources to make any innovation. "2S" allows large increases in output at very low cost. Between 1999 and 2006 Grace raised its capacity by 50,000 tonnes at the cost of one third of what its competitors would have had to pay. Meanwhile, production cost was cut by one eighth of the sale price per tonne. Cost of production is always the most important competitive factor in the fibre industry. " $2 S$ " has made Grace cost leader in viscose spinning.

The key inventions were completed in 1999, initiated and overseen by Feng Tao and implemented by him and 3 other key technical staff. How to protect them: patent or not? Patenting would mean invention disclosure but not necessarily perfect protection. It was unclear how effective the IP protection regime was going to be. On the other hand, " $2 S$ " is not a complex technology, and any industrial expert can decipher the technological secret through a close look. Imitation would be only a question of time for domestic competitors, with the circulation of personnel. Accordingly the top management decided to apply for a patent on " $2 S$ ". As the CEO commented: "This decision is risky. It is based on belief in law".

Grace patented this innovation in China with 1 invention and 15 utility patents, in addition to a series of design patents. The main patents were applied for in December 2000, and were granted in 2001 and 2002. They were introduced into production by Grace in 2002 and already generated RMB110m. new sales in 2003. In 2004 the $2 \mathrm{~S}$ technology was imitated by six competitors. Grace had to sue to survive. It won. The exploitation fees from licensing agreements and compensation for damage caused reached RMB109.6m as of end 2005. Grace would have preferred to avoid granting licenses and simply keep rivals out; but given that the infringing rivals were SOEs too, it was 'politically' obliged to let them have their place in the sun, at a price.

Grace depended entirely on the help of the Sichuan provincial IPR Bureau for the initial patent applications. It then rapidly built its own IPR competences. In spite of the relative simplicity of the key technological advance, the IP portfolio associated with $2 \mathrm{~S}$ is substantial. In the process of technological evolution, once a core technology has settled on a particular kind of design, further advances are concentrated in peripheral technologies. If the peripheral technologies of $2 \mathrm{~S}$ had been patented by competitors,

\footnotetext{
${ }^{8}$ In most of the coastal provinces, any surplus labour will be soaked up by the booming private sector. Innovation is of course not the easiest way of finding work for surplus workers: SOEs traditionally resort to diversification into already established product markets to find work for their surplus staff.
} 
Grace's dominant situation would have been compromised. Grace therefore quickly built a sound and solid multilevel IPR protection network. In 2003 an IPR office with seven employees was initiated - the director reporting directly to the CEO. There are also part-time 'IPR protectors' in every department, who play important roles in Grace's management of innovation projects. Potentially patentable inventions are kept absolutely secret until a patent application has been filed. Every employee in Grace has to sign a confidentiality agreement. We observed many slogans and rule-bulletins in the offices and workshops reminding the employees to pay attention to confidentiality in their daily work.

The local government continued to provide help for Grace's patent protection, for example in the cases of patent infringements (see above). The Sichuan IPR Bureau even set up an IPR database specifically for Grace. It is notable that all of Grace's 87 patents are domestic only. It has not applied for patents in advanced countries, where spinning is highly automated - nor in India or Pakistan, China's main rivals in the industry, where it feels that the lack of IP protection resembles China 20 years ago: Grace would lose more by the disclosure involved than it could hope to gain. Grace's patents, and its technological advances generally, are all 'home-grown' - based on in-house R\&D. But R\&D here should be understood broadly. Grace encourages invention by front-line users - production operatives. The S\&T department calculated for 2005 that $42.8 \%$ of all technological innovation projects were contributed by front-line users - not surprising given the emphasis on process improvement and the relative simplicity of the equipment.

\subsection{Hot tandem mill in CNEGC - a long march to independence}

No.2 Heavy Machine Factory was founded in 1958 in a heavyindustry hub in Sichuan; and renamed CNEGC in 1993. CNEGC is now a central state-owned 'backbone' enterprise - one of China's 21 domestic 'heavy machinery bases' - key manufacturers. By the end of 2006, it had over 12,900 employees and more than 1200 R\&D personnel. It has a particular specialisation in heavy plant for steel mills, the subject of this case. ${ }^{9}$

It should be noted that this industry is much more hightechnology than viscose fibre spinning. Steel plant falls into the category of 'machinery not elsewhere classified' - a medium-high technology sector, by the OECD definition, like, for example, motor vehicles or chemicals, though with rather lower R\&D intensity. Equipment for steel mills, like most of CNEGC's products, has been regarded as strategically important for Chinese industrial development: steel output was always a key measure of industrial development under 'socialism', and China is still far from moving out of the 'steel-intensive' stage of its development. CNEGC got the clearest proof of favoured 'insider' status - it was among the first group of state-owned enterprises funded and permitted to seek foreign help in 1979, just a year after the reform process began.

The hot tandem mill is perhaps the key set of equipment in large steel plants, and accordingly the leading product of CNEGC. Here, as across its product range, CNEGC found itself far behind the technological frontier. CNEGC's technology strategy in its first decade of 'catch-up' can be described as imitative. The classic indicators of dependence in technology strategy are joint ventures with the FFF technology provider, and reliance on one FFF for a whole 'bundle' of technologies (Section 2.1 above). CNEGC set up no JVs and used three different FFFs for mastering advanced techniques of casting and forging. At the same time it set up two important R\&D units, the Heavy Machinery R\&D Unit and Large-size Casting and Forging Research Unit. This was ambitious.

\footnotetext{
9 At the beginning of the case period, over half of CNEGC's output was steel equip-
} ment; it is now second, behind plant for electricity generation and transmission.
By 1990 CNEGC had developed detailed design capability - the ability to tailor a general design for the specific requirements of an individual customer - and reached international standards over a wide range of manufacturing processes. These capabilities steadily improved during the 1990s. Meanwhile it drew on eight foreign firms for product technology for steel plant alone: still imitation, but on a higher level. Nonetheless, the 1990s were a decade of deepening crisis. Small and relatively simple equipment, where it depended little on foreign technology, was open to newly-founded private firms, who duly took most of the market - and ravaged the profit margins on what CNEGC continued to make. Large items like hot tandem mills were safe from the private firms, but there CNEGC continued to rely on FFFs. There was a heavy price to pay for such reliance: as Mr. Zeng, vice general manager, said (interview, summer 2007), during this period CNEGC did $80 \%$ of the job but only received $20 \%$ of the profit.

To solve the $80: 20$ problem in hot tandem mills, CNEGC needed to become a one-stop contractor: provide a full service from product design, through manufacturing, to installation. The main obstacle to this aspiration was the hot coilbox. This is the key technology in the hot tandem mill, especially in modern hot strip steel mills, and patented by foreign firms, led by Hatch, in 69 countries - but not including China, as CNEGC found when it searched the patent records of SIPO. Hatch, which had developed it in the late 1970s, may have thought no-one in China capable of making it; or preferred not to divulge to SIPO the details of its manufacture. The hot coilbox was a 'black technological box' to CNEGC at that time - it had not been licensed to produce it, and knew little or nothing about the technology. CNEGC set up a hot coilbox project team in 1995, led by an experienced engineer, Mr Tang, and overseen by the deputy CEO in charge of technology. The main difficulty they faced was to understand the structure of the coilbox. Another issue was the manufacture of the mandrel at the core of the box, which was worked out, as to alloy composition etc., by a long series of trial and error experiments, and kept secret rather than patented.

By 1999 CNEGC had developed its own design of hot coilbox, which was different from foreign firms' in structure to some extent, and matched the requirements of Chinese domestic firms better. It proceeded directly to apply for patent protection in China; successfully, although at that point they had no patent office - they had to hire a patent consultant to do the job. Unfortunately CNEGC turned out to have invented round a moving target. By this point, foreign firms had improved the technology, bringing out a new type of mandrelless hot coilbox. In 1999 CNEGC set up a mandrelless hot coilbox project team - led by Mr Tang but with 3 protégés playing leading roles, and organised by the newly-formed Technical Centre - and in 2001 again succeeded in inventing round; again it patented it in China. By this time it was at the technological frontier not only in production but in design and development capacity: it continued work on hot coilboxes, and by 2007 developed another new mandrelless hot coilbox, and again patented it in China. CNEGC's success here solved not only its own problem, but a serious problem for the Chinese steel industry. The hot coilboxes available on the international market had not suited its particular conditions ${ }^{10}$ : CNEGC's did. Moreover CNEGC was able to make them for a price $30-40 \%$ cheaper than imported coilboxes. Due to such technological success and its ownership of the IP, CNEGC gradually took over foreign firms' role as one-stop contractor in this field. From 2000 to the end of 2008 , its hot rolling strip steel projects with patented hot coilbox technology created an output value of RMB6 bn., some $\$ 900$ million at 2008 exchange rates. It had established itself as a successful defensive innovator. As a result, in hot tandem mills it

\footnotetext{
${ }^{10}$ Long production line, large temperature difference between the head and tail of 'embryonic strip', and unstable quality.
} 
has more than $50 \%$ of the Chinese market, as well as substantial export sales to developed as well as to developing countries. Its net profits have risen dramatically, from an average of RMB18m in 2002-2005 to RMB354m in 2007-2010.

\subsection{Ascent with analogue, descent with digital: Changhong in TV}

Changhong was established in Mianyang city of Sichuan, in 1958. Until the 1980s its main product was radar for military planes; it then transformed itself essentially into a TV producer and as such passed out of military control into that of the provincial government, which became its largest shareholder. Unlike CNEGC, Changhong was not one of the favoured 'insider' firms during the 1980 s and 1990s. The three favoured firms in the TV industry entered joint ventures with foreign firms, made little effort at technological learning and became completely uncompetitive during the 1990s (Xie and Wu, 2003). Like CNEGC, Changhong did not set up joint ventures with foreign firms, and broadly chose an ambitious imitative rather than dependent strategy.

Thus, while it imported assembly lines from Matsushita of Japan - the first in 1979 - it put heavy emphasis on assimilating and understanding the technology employed: the Changhong engineers who worked with Matsushita's engineers on the installation and adjustment of the second assembly line in 1985 were in consequence able to develop their own process technology. 'From 1987 to 2000 it designed and manufactured by itself 13 state of the art assembly lines' (Xie and Wu, p. 1471). During the 1990s it used reverse engineering in combination with internal R\&D to learn how to design CTV electronics circuits. (By CTV we mean colour TV, of the old type - using analogue technology, and cathode ray tubes (CRT) for the screen display.)

By 1997 Changhong had 25\% of China's CTV market - more than the next two firms combined, and far ahead of all foreign brands. As Xie and Wu put it, Changhong learnt the art of assembly in 1979-1984, process engineering skills in 1985-1989, implemented technological adaptation in 1990-1995 and started acquiring product innovation skills after 1996. It was, in short, a model of successful technological learning. In the 1990s as in the 1980s we can speak of an imitative strategy, but at a higher level, with an increasing emphasis on in-house development.

Changhong was not one of the favoured insider firms, but nor was it the only 'outsider' which came in to challenge them. By 1992 it was facing six domestic rivals - all but one state-owned - and three joint ventures of state-owned firms with multinationals; by 1997 it faced another powerful rival (Haier) and four more joint ventures (Xie and $\mathrm{Wu}, 2003$ ). Its success was based on a cost leadership strategy, and accordingly it expanded its market share through price competition, which it initiated in 1989. With little product differentiation, this grew more intense during the 1990s, as the number of domestic manufacturers increased, while from 1992 onwards, tariff protection of the Chinese market declined, from an initial level of 40\%. Fierce price competition escalated in 1996 to full-scale price war. Broadly speaking, Changhong's outsider rivals could match its price and costs, but not its quality - conversely for the insiders. Still, state-owned competitors could not simply be driven out of the market by losses - Changhong had to acquire weaker rivals, and the cost burden of their operations, in order to take their market shares (Xie and $\mathrm{Wu}, \mathrm{p} .1472$ ).

During the late 1990s, as Changhong closed on the (then) frontier in CTV, it moved towards a defensive technology strategy, strengthening its relationship with domestic research institutes and universities to get access to the latest technologies (Xie and $\mathrm{Wu}$ ). But it was trying to do so for minimal expenditure. Through the late 90 s its average R\&D intensity was less than $2 \%$ of sales - niggardly for a high-technology industry. Meanwhile it raised large sums on the stock market to improve its manufacturing capability. ${ }^{11}$ The decade closed in 1999, accordingly, with another price war unleashed by Changhong.

The then CEO and chairman Ni Runfeng, in place since 1985, seems to have been aware that a more technologically ambitious strategy was required. He knew the man to lead it. Zhao Yong was a native of Mianyang whose excellence at physics had led him to a lectureship at a top university, Tsinghua. In $1993 \mathrm{Ni}$ persuaded Zhao to join Changhong. By 1995 he was chief engineer, and in 2000 took over as CEO. He decided to ramp up R\&D and focus on product development in the latest 'big thing' within CTV - rear projection. Conscious of financial constraints, he decided to cut back production to generate the cash for R\&D by reducing the very large inventory.

The provincial government however decided that production cutbacks would have an unacceptable effect on local employment and provincial GDP. Zhao was transferred to become Deputy Mayor of Mianyang. Ni returned. There began a strategic hiatus of three years (2001-2003). Both Zhao's key initiatives were revoked and Changhong simply tried harder at its old cost leadership strategy: aggressive sales drive at home, cut-price sales abroad, and process improvement.

This should have destroyed Changhong. As we see below, the pause in the catch-up process coincided with a world-wide paradigm shift in consumer electronics technology. To spend less money and effort on catch-up just as the frontier was accelerating away should have brought decline into, at best, dependence. Changhong's current TV production is indeed more dependent on licenses from FFFs than before, but its overall strategy is far from being dependent. This was made possible by an important change in national economic policy: the drive to develop the West. The national government had become increasingly concerned at the relative stagnation of the inland, Western provinces. Sichuan is the West's industrial powerhouse. By 2000 central funds were flowing in freely, but the emphasis was initially on infrastructure. Phase Two began in 2004 - when Sichuan's most promising manufacturing firms, including Changhong, would have money pumped into them. Changhong needed top management appropriate for technological ambition now. In October 2004 Zhao returned as chairman. The new CEO, however, was the ex-Finance Director, Liu Tibin. As we shall see, Changhong now moved to a 'financially-turbocharged' defensive strategy. A 'finance man' as CEO could best manage the massive inflows of capital required for the strategy.

The situation in late 2004 was bleak. With WTO entry decreasing protection further, Changhong was steadily losing market share in TVs to sets made abroad or made in China with foreign brands. While it had apparently been catching up the FFFs, during the 1990s, the DTV revolution had been happening - the arrival in TV of digital technologies. DTV began broadcasting in the developed economies between 1998 and 2002, with analogue due to end between 2005 and 2012; in China, between 2007 and 2015. DTV standards have come into being, covered by a large number of patents. Meanwhile, there has been a revolution in display technology: CRT has been displaced by LCD (liquid crystal) and PDP (plasma), with patents owned by mostly Japanese and Korean FFFs.

Now the Chinese TV firms must use DTV, and the new display technologies. The dominant FFFs are in a position to sue the Chinese firms for royalties; and they do. The royalty for a licence to use the ATSC (American) standard is \$30 US per set. Using that standard, ${ }^{12}$ the royalty will cost Chinese TV firms $\$ 1$ billion per annum (Changhong interview, IP Office Director). In spite of licensing, China's domestic DTV producers have been losing the local

\footnotetext{
11 Wu Guisheng (2009), personal communication.

12 Which they do only on exports; on the domestic market the European standard is used.
} 
Table 5

Cross-case comparison 2: findings consonant with initial propositions and new insights generated through case studies.

\begin{tabular}{|c|c|c|c|}
\hline & Grace & CNEGC & Changhong \\
\hline \multicolumn{4}{|l|}{ Section 2.6 'proposition' } \\
\hline $\begin{array}{l}\text { Corporate governance influences } \\
\text { choice of strategy }\end{array}$ & $\begin{array}{l}\text { Close commitment of local } \\
\text { government allows offensive strategy } \\
\text { - which in this sector is affordable }\end{array}$ & $\begin{array}{l}\text { Privileged position as 'central SOE' } \\
\text { allows ample funding of defensive } \\
\text { strategy and 'pre-defensive' R\&D }\end{array}$ & $\begin{array}{l}\text { ‘Outsider' status due to provincial } \\
\text { government ownership encourages } \\
\text { imitative strategy but limits funding } \\
\text { till central government policy changes } \\
\text { in } 2004\end{array}$ \\
\hline $\begin{array}{l}\text { Imitative versus dependent strategies } \\
\text { in early catch-up: outcome }\end{array}$ & $\begin{array}{l}\text { [Catch-up proves irrelevant and } \\
\text { unnecessary. See New insights] }\end{array}$ & $\begin{array}{l}\text { Broadly imitative strategy with diverse } \\
\text { licensing and early R\&D. Caught } \\
\text { between FFF blockade on higher-tech } \\
\text { products and POE competition on } \\
\text { lower-tech. }\end{array}$ & $\begin{array}{l}\text { Strongly imitative strategy achieves } \\
\text { cost leadership but profit undermined } \\
\text { by dependent rivals. Little is available } \\
\text { to prepare for defensive strategy. }\end{array}$ \\
\hline Defensive strategies in late catch-up & [As above] & $\begin{array}{l}\text { Imitative evolves into defensive } \\
\text { strategy which is highly successful. }\end{array}$ & $\begin{array}{l}\text { Given ( } 2 \text { ) above and ( } 4 \text { ) below, } \\
\text { defensive strategy cannot succeed } \\
\text { before } 2004 .\end{array}$ \\
\hline IPR and level of technology & $\begin{array}{l}\text { IPR protects against Grace's domestic } \\
\text { rivals }\end{array}$ & $\begin{array}{l}\text { FFFs' IPR forms initial patent blockade } \\
\text { but 'inventing round' proves possible; } \\
\text { own patents protect CNEGC's position. }\end{array}$ & $\begin{array}{l}\text { Changhong is crippled, after } 2000 \text {, by } \\
\text { FFF patent blockades in digital and } \\
\text { display technologies. }\end{array}$ \\
\hline \multicolumn{4}{|l|}{ New insights } \\
\hline Corporate governance and finance & $\begin{array}{l}\text { An SOE which is near-bankrupt still } \\
\text { has personnel resources with which to } \\
\text { innovate }\end{array}$ & $\begin{array}{l}\text { 'Military' firms avoid classic faults of } \\
\text { SOE governance. They are run by 'red } \\
\text { experts' committed to the enterprise. } \\
\text { 'Inclusive', relatively bottom-up style } \\
\text { of management }\end{array}$ & $\begin{array}{l}\text { Military tradition (see CNEGC) of } \\
\text { 'organic' corporate culture and style of } \\
\text { management gives initial dynamism. }\end{array}$ \\
\hline $\begin{array}{l}\text { Strategic trajectory chosen, and } \\
\text { reasons for it }\end{array}$ & $\begin{array}{l}\text { Lower labour cost makes catch-up to } \\
\text { FFF automation, inappropriate, and } \\
\text { points to independent path of } \\
\text { innovation }\end{array}$ & $\begin{array}{l}\text { 'Military' governance causes stress on } \\
\text { independent strategy of development }\end{array}$ & $\begin{array}{l}\text { From 2004, central government pours } \\
\text { money into industry in western } \\
\text { provinces: thus 'turbo-charged' } \\
\text { defensive strategy becomes financially } \\
\text { feasible }\end{array}$ \\
\hline
\end{tabular}

market: thus in LCD TV, domestic brand share fell from over $60 \%$ in 2005 to below $50 \%$ in 2008. Thus Chinese CTV firms are LCFs in the field of TV technology once again.

In 2005 , in order to try to find weak points in the technological blockade in the display field, Changhong established a database of multinational patent information and a system to analyse patent information. It employed a US IP management firm to collect and analyse the patent distribution all over the world in LCD and PDP. It concluded that there were fewer patents and more uncertainty in PDP than LCD. So it decided to invest in PDP. In general it decided to include activities further up the value chain than its traditional focus on assembly. Changhong also decided to diversify within consumer electronics. This time, in 2004-2005, they opted for mobile phone handsets - which had much in common technologically with TVs as they now were. Unfortunately mobile phones have for long used LCD rather than PDP, so Changhong's focus on PDP was no use to its new mobile phones division.

The defensive strategy that then developed had three main elements:

- Build up own R\&D in close cooperation with the local science base - also now well-funded. ${ }^{13}$ Changhong's R\&D intensity was 6\% during 2004-2006 - three financial years in which it lost over RMB1bn. per year, on average.

- Join the developing trend by which rich and/or favoured firms in China buy technology by buying foreign firms. In April 2008 Changhong bought the Korean university spin-off company Orion - which had been set up in 2000 to commercialise promising OLED (organic light-emitting diodes) technology. OLED looks like becoming the dominant display technology across the board, starting with handsets. However the great challenge was to integrate Orion with Changhong so that its technology was absorbed

\footnotetext{
13 Sichuan's capital, Chengdu, hosts the University of Electronic Science and Technology of China (UESTC).
}

by the whole firm in China. Significantly, as of Sept 2011 the deputy CEO of Changhong was the CEO of Orion.

- Set up production lines for PDP and OLED display, making heavy use of licensed technology (construction started in 2008). The development of production experience in these fields could not wait for anything like 'patent parity' with FFFs.

Changhong has also zealously participated in the development of independent Chinese digital technology standards, contributing inter alia a 'sink chip', a key component for mobile DTV. In April 2007 Changhong also joined with nine other Chinese CTV manufacturers to establish a joint venture which administers the technological alliance patent pool the ten firms have formed, and negotiates with FFFs.

\section{Discussion}

How far are our case findings consonant with our propositions? How far do they yield insights which go beyond them? We summarise our findings in Table 5, and discuss them below.

\subsection{Grace}

Clearly this company was exceptional in its rapid movement from 'zero to hero' within the Chinese viscose spinning industry, and the main exceptional element was the inspired leadership of Feng Tao. Permissive factors included the arrival of functioning IPR laws together with the support of local government, and the availability of adequate resources for innovation, partly due to the obligation to 'carry' redundant labour even when technically nearbankrupt. This case showed unexpected limits of applicability of the original propositions:

P1: 'Catch-up for LCFs is easier, the lower the technological level of the sector, internationally.' Yes, but in this labour-intensive low-tech industry, Grace did not want to catch up to the point of adopting the existing 'advanced' automated spinning technology: with its low labour costs that would not have been profitable. (This may well have broader applicability in low-technology industries, 
since labour intensity is usually high.) This meant that the trajectory on which it wished to travel was one on which any innovation would be offensive from the beginning - and that was what the $2 \mathrm{~S}$ technology represented.

P3: 'Defensive and offensive strategies are more likely to be successful where finance is plentiful, and cheap....; no doubt, but though finance was not plentiful for Grace, it turned out that in this sector it was possible to contrive an effective offensive strategy with little more than the employees that as an SOE Grace was not allowed to fire (Fig. 2).

\subsection{CNEGC}

Unlike Grace, CNEGC was in a sector in which the aim, for a strong firm, was and must be catch-up, all the way - even if it turned out to be convenient to develop products for Chinese customers which were somewhat different from what FFFs might want. Unlike Grace, it was not through the accident of exceptional leadership that CNEGC was successful - success, though not inevitable, was 'in the script', given its membership of an elite group of favoured 'insider' firms. Its success conforms in some respects very well to our propositions:

P2a: 'If dependent strategies are indeed followed by major late-comer firms, this will weaken the market position of other latecomer firms following imitative strategies, and thus their ability to make these strategies succeed'. Heavy machinery was a tightly restricted sector: there was initially little or no competition for its heavy steel plant, which was difficult to manufacture. So its choice of imitative strategy was not undermined by competition from other LCFs following dependent ones. The undermining was done by small new private firms successfully imitating its more easily-manufactured products. The main value of the patent on its first hot coilbox was to protect itself against imitation there - just as for Grace. Then, as its catch-up proceeded, 'Imitative strategies ... become more difficult, because of ... reduced co-operation .... Further catch-up therefore requires a switch to defensive ... technology strategy [which is] more likely to be successful following imitative strategy.' It was indeed forced to move 'up' in strategy, and did indeed succeed, following on from its imitative strategy.

'Whereas, for the pioneer, patents are often a critical method of protecting a technical lead and retaining a monopolistic position, for the defensive innovator they are ... to weaken this monopoly. .... to avoid being excluded from a new branch of technology.' (Freeman, pp. 267-268). We can say that it was when the mandrelless hot coilbox project began, in 1999, that CNEGC's strategy moved from imitative to defensive.

P1: CNEGC's success is the less surprising because its sector is at the bottom of the medium-high tech category, in R\&D intensity: the FFFs were not advancing the frontier very fast.

But what our propositions do not explain is why CNEGC chose the right strategy initially. Insider firms notoriously avoided imitative strategies (Lu and Feng, 2004): why did not this one? And why did it execute it and the subsequent defensive strategy so well? ${ }^{14}$ Further interviews shed light on this. There is a pattern of corporate governance which is typical but not universal in central SOEs: CEOs are effectively senior officials, and as such are rotated among top firms and between them and ministries, typically spending around five years in one posting. Accordingly they have a career interest in the quick results available from dependent strategies (Liu and Tylecote, 2009). But CNEGC has military origins and much of its output is still for military uses. Military firms are treated differently:

\footnotetext{
14 Its early establishment of R\&D labs can however be reconciled with the propositions, as the sort of thing that a favoured insider firm is adequately funded to do.
}

the technological demands upon them are such that they need to be run by 'red experts', you hong you zhuan: expert engineers patriotically committed to their political duty, who would normally be promoted within the firm and end their careers within it. We found precisely this 'military' pattern of corporate governance, within CNEGC. ${ }^{15}$ Further, innovation for military purposes has been profoundly influenced by the efforts to develop nuclear weapons and satellites - which drew on Chinese-American returnees and their cultural experiences within US high tech firms (Zhang, 1999). Necessarily a military firm has to avoid dependence on foreigners, and it achieves its ambitions through a rather bottom-up style of management - bottom-up in achieving goals which inevitably are set, top-down. The hot coilbox project was imposed on CNEGC, military-style, from the very highest level, and treated by those selected for it as a patriotic duty (Fig. 3).

\subsection{Changhong}

The Changhong case seems to support the core of the first proposition:

P1: 'catch-up is easier, the lower the technological level of the sector, internationally'. 'A developed IPR system .... makes it easier for Northern 'frontier' firms to defend their advantage against a late-comer firm.' The FFFs in its (high-tech) sector have used IPR very effectively to defend their positions in the new areas of digital and display technologies. Likewise:

P2a: in this sector of Chinese industry, FFFs were initially happy to enter joint ventures and grant licenses. This made 'dependent strategies ... highly successful in rapidly improving static technological capability. ...this will weaken the market position of others following imitative strategies... ${ }^{16}$ Changhong therefore never made the profit it deserved from the success of its imitative strategy and was thus unable, in the 1990s, to fund a defensive strategy in good time.

The propositions thus go a long way to explain the critical difficulties that Changhong faced in 2000 and after. What they do not do is to explain its key strategies and policy decisions. As with the other cases, further research has offered insights into these. We could already say that as an 'outsider' firm Changhong lacked funds, and perhaps authorisation, for joint ventures with FFFs, so that it was driven towards imitative strategies. But it was also a military firm in origin, and that meant that it began with an inclusive, bottom-up culture and governance - an excellent basis for success with imitative strategy. The peculiarities of Chinese SOE finance and governance also help to explain the twists and turns after 2000, in face of crisis. Being by that time under the control of the provincial government, it was, as we saw, politically unable to shed labour. Thus Zhao's attempt in 2000 at 'defensive strategy on the cheap' was quickly quashed. Then when the central government poured funds into its province from 2004, it was finally, belatedly, funded to follow a defensive strategy, indeed a 'financially-turbocharged' one, and did so - Zhao being called back to lead it.

Changhong's is the most complex case - thus its length - and the most discouraging. A firm which was hailed in the early years of this century as a highly successful example of catch-up, based on a well-worked-out imitative strategy, soon found itself back far behind the frontier, and only able to progress again towards it through massive central government subsidy - 'financially turbocharging' a new defensive strategy. For Changhong, the main

\footnotetext{
15 At least the last three CEOs have been CNEGC 'lifers'.

16 The readiness of other SOEs to enter the TV market in the 1990s, using dependent strategies, arose also from the peculiarities of their corporate governance and finance. Seeking to find work for surplus workers they were not allowed to fire, they diversified anywhere they easily could; profit was not required.
} 


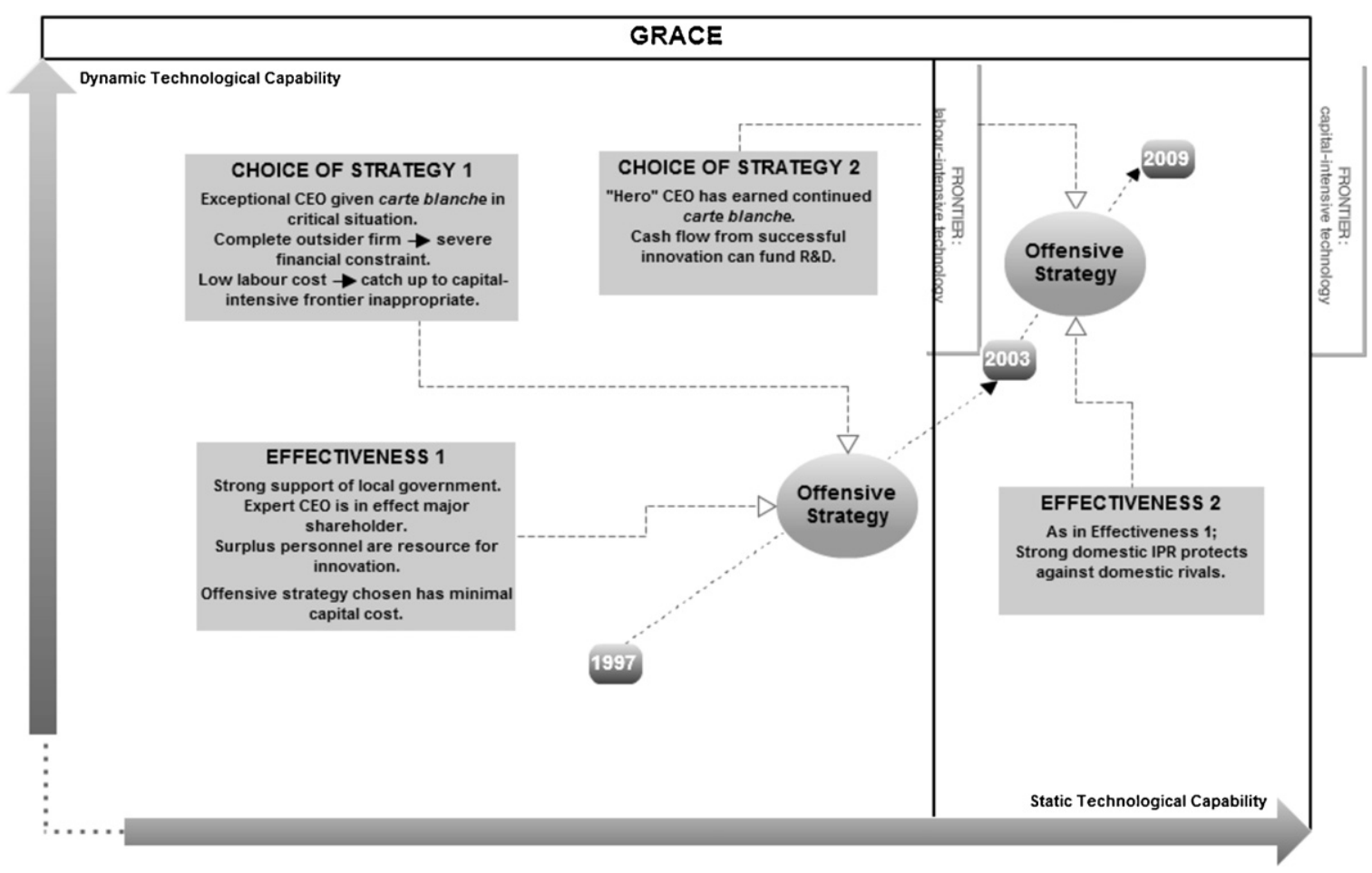

Fig. 2. Grace: offensive strategy from the beginning.

significance of IPR was as the basis of a patent blockade erected by FFFs against it and other Chinese LCF firms in DTV. It would no doubt be able, if it invested enough in its defensive strategy, to use the resulting patent portfolio as Grace and CNEGC had done, to protect it against 'imitative' domestic rivals - and even as a bargaining chip with FFFs. But as it stands, it is a study in failure and the failure is that of the standard-bearer for a whole sector (Fig. 4).
It is therefore important to consider how representative Changhong is. We saw in Table 3 that in the TV sector, China has a revealed technological advantage $(R T A)$ around a third of its overall level. These figures thus tend to confirm the particular technological weakness of Chinese firms in the TV sector, compared to lower-tech sectors (in Grace's sector the RTA figure shows, conversely, relative strength; and in CNEGC's sector, an intermediate position).

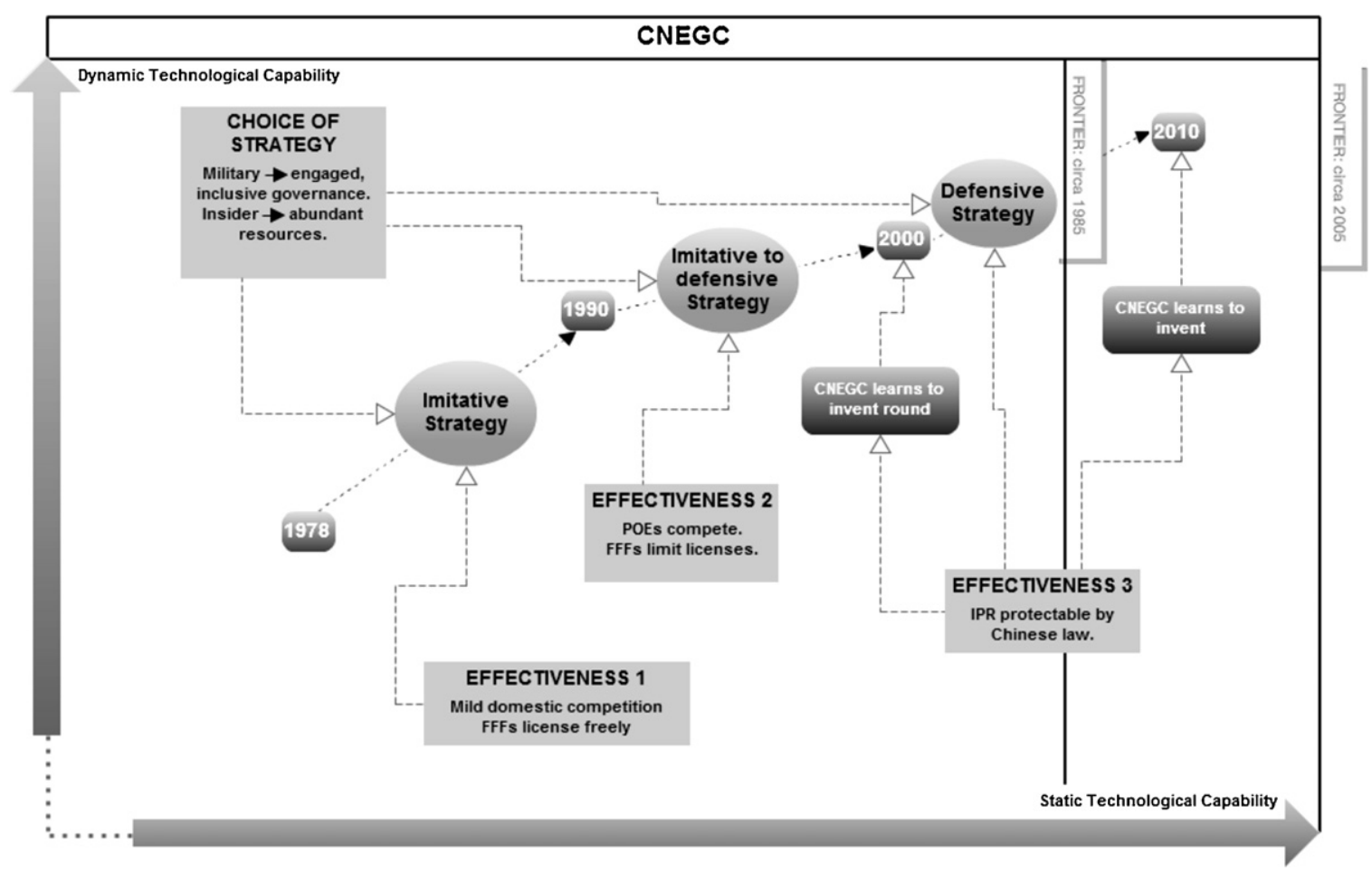

Fig. 3. CNEGC: catch-up by the book.

Please cite this article in press as: Xiao, Y., et al., Why not greater catch-up by Chinese firms? The impact of IPR, corporate governance and technology intensity on late-comer strategies. Res. Policy (2013), http://dx.doi.org/10.1016/j.respol.2012.11.005 


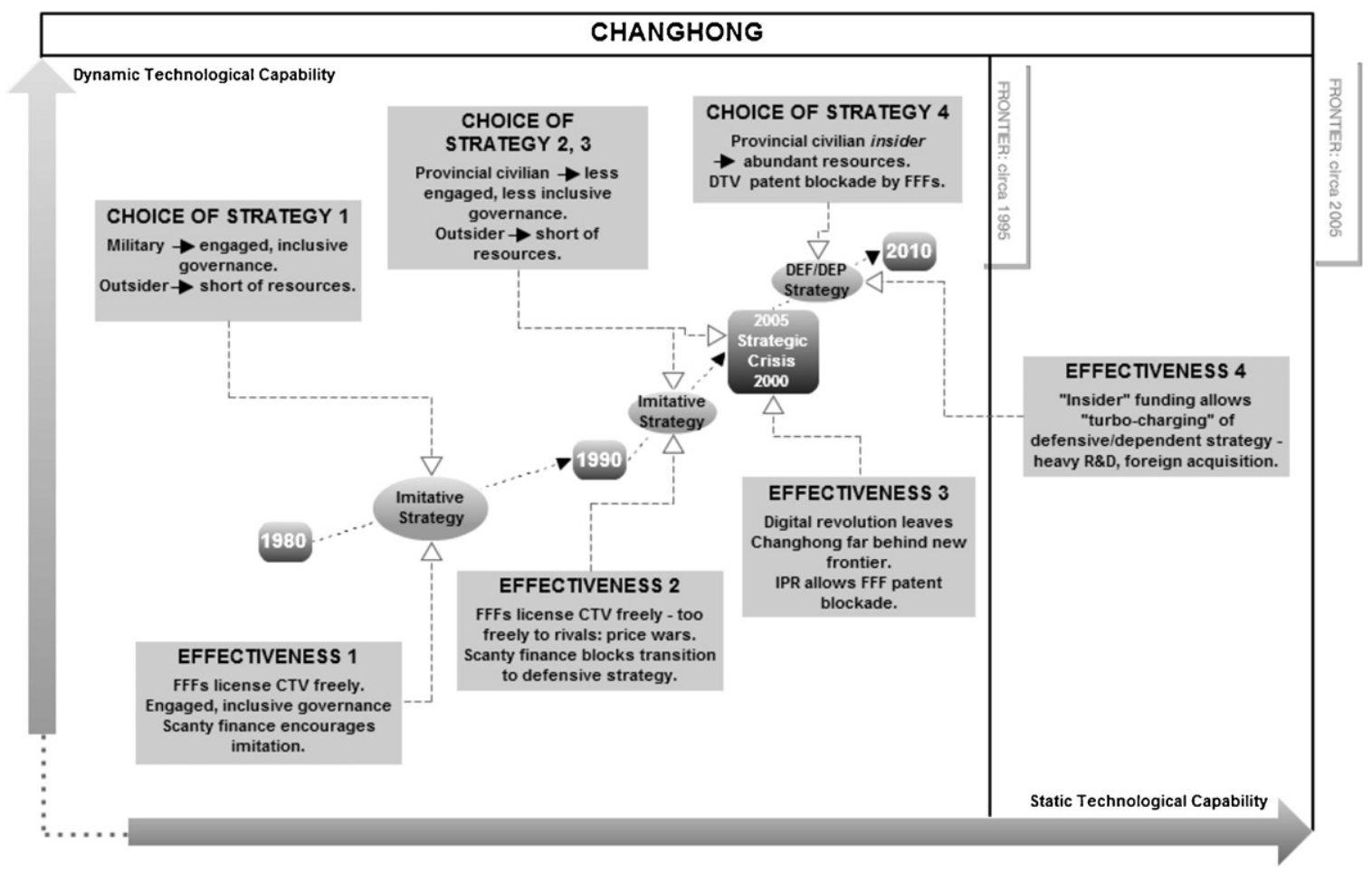

Fig. 4. Changhong: catch-up derailed - or deferred.

The weakness in TV appears to be general for high-technology sectors, to judge by the trade data. The crude trade data is thoroughly misleading on China's position here. Thus the share of high-technology exports, mostly ICT, in total exports rose from 7.9\% in 1995 to 31.4\% in 2009 (Xing, 2011). Given that total exports were themselves rising rapidly, this would appear a remarkable performance. However between 1995 and 2009 the share of wholly-Chinese-owned firms in exports of high-tech products fell from an already low $21 \%$, to $17 \%$ (Xing, 2011); in 2008 68\% and $18 \%$ of high-tech exports were produced by fully foreign-owned and partly foreign-owned firms respectively (Xing, 2011). The export data, moreover, is by turnover. Given the high dependence of Chinese manufacturers on imports of components, and equipment, the value-added picture must be far worse. Given the weak IPR position of Chinese manufacturers, we would expect their position in terms of profit to be worse still. It is. In 2009 profit margins in 'computers and communication technology' were around or below $3 \%$, and $82 \%$ of exports of computer and communication technology are assembled from imported parts and components (Xing and Detert, 2010). China's export of iPhones (US $\$ 4.6$ billion) was $1.2 \%$ of its total high-tech export, but the value added in China was merely 3.6\% ( $\$ 165.6$ million), or \$6.50 each (Xing and Detert, 2010). An indicator of the domestic Chinese weakness is R\&D intensity, since R\&D tends to be performed near a firm's home base: the R\&D intensity (over turnover) of radio, television and communications equipment in mainland China in 2010 was $1.4 \%$ (cf. USA, 14.7\%) and for computers and office equipment in 2009, 3.5 (USA, 13.6) (http://stats.oecd.org/index.aspx). ${ }^{17}$

\footnotetext{
17 These two sectors together made up 74.9\% of the value added of high-technology industry in China in 2008 - the other sectors, in descending order, being pharmaceuticals, medical equipment and scientific instruments, and aircraft and spacecraft. The R\&D intensity figures for radio, television and communications equipment are lifted by the sparkling performance of two mainland Chinese firms, Huawei and ZTE,
}

Let us now put Changhong, and the Chinese TV industry generally, in international context. Kim (1997) generalises about the catch-up process in Korean manufacturing. Large conglomerate firms (chaebol) typically behaved as 'apprentices' (of FFFs). For them, accordingly, the first stage of catch-up would involve bundled ('packaged') technology transfer from FFFs. But this was not intended to be a continuing dependent strategy. They 'deployed deliberate and aggressive strategies to acquire their own technological capabilities by striving to assimilate foreign technologies from the outset' (p. 209) - for example, by employing foreign personnel. Typically, the second major investment in technology transfer would be unbundled (Kim's Table 9-2); Kim's description from this point on, corresponds rather well to our imitative strategy, morphing into defensive. The change from imitative to defensive strategies by chaebol, from the mid-1980s onwards, was accompanied by much stronger IPR protection (Lee and Kim, 2010) - much as in the CNEGC case.

If large Korean firms could choose, and succeed with, 'apprentice' strategies which were initially hybrids of dependent and imitative, it is striking that Chinese firms in early catch-up appeared to go clearly for one or the other. Thus imitative strategies were followed almost only by 'outsider' firms, such as Changhong, Chery and GTC (Liu and Tylecote, 2009), Lenovo (Lu and Feng, 2004), Huawei (Xue and Liang, 2010) and ZTE (Tylecote et al., 2010) while those who followed dependent ones were mostly (but not only) favoured 'insider' firms - e.g. SAIC (Liu and Tylecote, 2009), and Dongfeng Auto, Panda, Beijing-International, and Shanghai-Bell (Feng, 2010).

How can we explain the difference? We may start from the proposition that the Korean chaebol path, as described by Kim, roughly dependent-imitative-defensive in Freeman's terms, was

in telecoms capital equipment. As we saw in the Introduction, their sub-sector is a special case, TV is much more typical. 
superior: fast and effective. 'Apprentice' strategies gave quick familiarity with advanced production technology through the initial 'bundles', and then the switch to unbundling prepared the firm for early independent development. ${ }^{18}$ But corporate governance and finance were key here, because the superiority was long-term: this was not a quick route to profit. Perhaps the most striking and successful example of catch-up in IT hardware is the Korean electronics industry, led by Samsung. 'late-comers should be committed for the long term to the business they enter, and therefore be prepared to withstand. . ..losses ....Samsung experienced a prolonged period of losses in the early 1980s [in chip-making] until it broke even in 1987. LG went through an even worse experience .... until it recouped most of its sunk investment by 1993 . ... crosssubsidization was perhaps the most crucial factor in the Korean companies' success' (Cho et al., 1998, pp. 502-503).

In Korea the chaebols' controlling shareholders had long-term ambitions for their enterprises, and they had other, cashgenerating, divisions from which cross-subsidies could come - as well as cheap loans from government-controlled banks, and some export subsidies (Kim, 1997). They bear out the latter part of P3: 'Defensive and offensive strategies are more likely to be successful where finance is plentiful, and cheap, and where finance and governance display strong industrial expertise - particularly in higher-tech sectors.' As we saw above, in China the typical 'insider' firm would have plentiful finance, but certainly not expert governance.

Chinese 'outsider' firms faced a quite different but equally fatal problem, which we saw in the case of 'pre-2004' Changhong. Whatever the precise nature of their corporate governance, they were not funded either externally or internally (through conglomerate cross-subsidy) to sustain them in loss-making production activities for years while spending heavily on R\&D. They needed to generate cash on the way up. Why should they not have done this on the protected domestic market, as Huawei and ZTE did? Because as we saw, these two firms were in an exceptional sector. In most other sectors there was severe competition from firms following dependent strategies - particularly the quickest and most dependent version, joint ventures. This, as we saw in Section 2.3, is quite different from the experience of Japan in the corresponding period (ca.1950-1980) - another country with a large domestic market, but where there was negligible foreign investment even of the joint venture type. ${ }^{19}$

In this light, let us return to consider CNEGC's success. First, its sector was not high-tech, but medium-high. ${ }^{20}$ That meant the speed of progress required for catch-up was less, and the effort also. Second, the peculiarities of its corporate governance (broadly understood) made it rather similar to a Korean chaebol in its technological ambition - while as an insider firm it was similarly well-funded, too. An interesting comparison is possible with another medium-high tech sector - the largest one, motor vehicles. The Chinese firms operating in this sector divide quite neatly into typical 'insider' and typical 'outsider' firms, and thus far have shown the classic weaknesses of their types (Lu and Feng, 2004; Feng, 2010; Liu and Tylecote, 2009). The industry as a whole, rather like the television sector, has shown how all firms lose when too many compete. Between 2004 and 2012 new car prices fell by more than $30 \%$, and foreign brands (mostly produced in joint ventures)

\footnotetext{
18 In fact, this sequence is less important than the 'deliberate and aggressive strategies. . .to assimilate', if we compare the account of Korea with that of China in Lee and Kim (2010) and Xue and Liang (2010).

19 Much the same could be said of the United States in its catch-up period during the 19th century (Mowery, 2010).

${ }^{20}$ In fact, 'machinery not elsewhere specified' is at the bottom of the OECD 'medium-high tech' category in terms of R\&D intensity.
}

maintained over $50 \%$ of light vehicle sales on the Chinese market - a dominance which by 2011 was increasing (Economist, 2012). This was in spite of longstanding government determination to build a domestic industry with three or four globally-competitive auto firms with their own brands and technology (Anderson, 2012).

\section{Conclusion}

This paper used the intellectual property and technology strategy of three Chinese firms as a point of entry to the debate on technological catch-up at firm level: 'How should 'late-comer firms' in developing economies manage their development of technological capability (and within it their IP) strategically, in order to become fully competitive internationally?' We asked, how did our firms manage it, and why, and with what outcomes? The answers were framed within Freeman's taxonomy of strategies - dependent, imitative, defensive, offensive - with the expectation that corporate governance and finance, the state of IP protection, and the technological level of the sector, would influence

- the early-stage choice between dependent and imitative strategy;

- later on, when and how effectively the firm would move to a defensive strategy.

Our first case, Grace in viscose spinning, almost burst out of the framework of propositions by presenting a move direct from zero to hero: from a near-bankrupt SOE owned by a lower tier of government, going nowhere technologically, to successful offensive strategy. This was possible, in Grace's low-tech area, because the technological trajectory on which it was operating was distinct from that of advanced economies - more labour-intensive. Catchup was therefore not required: it was, in labour-intensive spinning, effectively at the frontier already. We were at all events able to identify the corporate governance conditions which made Grace's success possible: engagement by local government, incentives for top management, and spare labour which could not be fired. But clearly the accident of an exceptional CEO being available, was crucial. We could also note that its path-breaking innovation would have been very quickly copied, and thus from Grace's point of view devalued, but for China's adoption of effective IPR in the late 1990s. Grace made telling use of the new legislation. Given its distinct technological trajectory, foreign frontier firms' (FFF) IP could not pose a problem.

What Grace achieved could not have been predicted for it, but we can see that there are many potential Graces in China: firms operating in low technology sectors, which might be capable of offensive or defensive innovations, and thanks to IPR legislation can profit from and then improve upon them.

CNEGC in heavy steel plant made a striking contrast to Grace: here was a firm where successful technological development was expected, and funded, as a particularly privileged member of the centrally-owned SOE elite, and one moreover with military connections. And there was a great deal of catching up to be done. As a 'military firm' it was bound to prefer the relative independence of an imitative strategy. But imitation - in the case of the hot coilbox - required a heavy development effort, which morphed into a full-fledged defensive strategy. The successful development of successive types of hot coilbox gave CNEGC profitable access to large and growing markets in which it was protected by its patents, particularly from domestic imitators. China's acceptance of IP protection made this possible. FFF IP again posed no major problem, largely because CNEGC was capable of 'inventing round' it.

What CNEGC achieved could then indeed have been predicted for it; but unfortunately there are not many CNEGCs in China: firms 
operating in medium-high technology sectors with the particularly dynamic 'military' corporate governance that we identified in this firm, and the excellent access to funds of the most favoured centrally-owned SOEs.

There are, on the other hand, a large number of potential 'pre-2004' Changhongs in China, in the sense of 'outsider' firms operating in more-or-less high-technology sectors. These are privately-owned firms, or SOEs, owned by provincial or local government: in either case they might have competent corporate governance, though the 'inland' SOEs would be constrained in firing redundant employees. Whichever sub-category they came into, they would all be financially constrained in their technology strategy. So they would not be able to do what the Korean chaebol had done, take the fastest route to catch-up, an accelerated sequence of (semi-)dependent-imitative-defensive, because they would have no source of large amounts of risk capital prepared to endure a long uncertain wait for profitability. They would need to generate the necessary cash as catch-up proceeded. The ideal arena for such cash generation should be a large protected domestic market, which is what mainland China used to offer. We saw nonetheless that the conditions within the Chinese domestic market were generally not favourable for this - there was too much competition from firms with access to FFF bundled technology. The 'financially-constrained outsider' would probably need to economise by unbundling even at the beginning, when bundling would have been quicker, and they would not be able to move quickly and decisively, but expensively, to a defensive strategy. Meanwhile, most insider firms - which were adequately funded - suffered from poor corporate governance, which made them fatally attracted by dependent strategies.

In consequence, the failure of the 'pre-2004' Changhong is all the more sobering because of its success during the 1990s. If such a successful firm could not complete its catch-up, what hope for the rest? And indeed as the statistics for Chinese high-technology industry indicate, the rest have generally failed. As we saw above, the largest medium-high-technology sector, motor vehicles, has shown rather poor Chinese performance also.

What are the implications for late-comer firms outside and beyond China - and their governments? Chinese firms seem not to have produced a model of catch-up that in any way supplants or even matches the Korean one, which as we saw revolved around 'deliberate and aggressive' technology assimilation. Corporate governance and finance seem to be key in explaining why. If a developing country's government cannot contrive corporate governance and finance as favourable as in Korea (and in CNEGC), it has all the more reason to avoid the situation which developed in the Chinese television and, to a lesser extent, motor vehicle industries. There, Chinese firms following imitative strategies and aspiring to defensive ones, such as Changhong in TV and Chery in auto, faced debilitating competition from firms following dependent strategies with bundled technology, mostly in joint ventures with foreign firms. "When you dine with the devil, you need a long spoon.' Foreign frontier firms are not the devil, but LCFs or their governments may need to keep them at a distance.

\section{References}

Anderson, G.E., 2012. Designated Drivers: How China Plans to Dominate the Global Auto Industry. Wiley, New York.

Becker, H.S., 1958. Problems of inference and proof in participant observation. American Sociological Review 23, 652-660.

Bently, L., Sherman, B., 2004. Intellectual Property Law, 2nd ed. Oxford University Press, Oxford.

Burgess, R.G., 1984. In the Field: an Introduction to Field Research. Routledge, London.

Cai, J., Tylecote, A., 2008. Corporate governance and technological dynamism of Chinese firms in mobile telecommunications: a quantitative study. Research Policy $37,1790-1811$
Cho, D.-S., Kim, D.-J., Rhee, D.-K., 1998. Late-comer strategies: evidence from the semi-conductor industry in Japan and Korea. Organization Science 9 (4), 489-505.

Comish, W.R., 1996. Intellectual Property, Patent, Copyright, Trademark and Allied Rights. Sweet \& Maxwell, London.

Cooke, F.L., 2002. Ownership change and the reshaping of employment relations in China: a study of two manufacturing companies. Journal of Industrial Relations 44, 19-39.

Cusumano, M.A., 1985. The Japanese Automobile Industry: Technology and Management at Nissan and Toyota. Harvard UP, Cambridge, MA.

Economist, 2012. Chinese carmakers: still in second gear. Economist, 65-66, May 5 th.

Eisenhardt, K.M., 1989. Building theories from case study research. Academy of Management Review 14, 532-550.

Fai, F.M., 2005. Using intellectual property data to analyse China's growing technological capabilities. World Patent Information 27, 49-56.

Feng, K.D., 2010. Catching up or being dependent: the growth of capabilities among indigenous technological integrators during Chinese development. Ph.D. Thesis, University of Sussex, UK.

Freeman, C., 1992. Economics of Innovation, 2nd ed. Routledge, London.

Gao, X.D., 2005. Technological capability development: Follow the right sequence or do the right R\&D (Jishu ChuangXin NengLi PeiYang: TeDingde PeiYang ShunXu HaiShi YouXiaode R\&D). Science of Science and S\&T Management (in Chinese) 6, 64-68.

Kim, L., 1997. Imitation to Innovation: The Dynamics of Korea's Technological Learning. Harvard Business School Press, Cambridge, MA.

Lee, K., Lim, C., 2001. Technological regimes, catching-up and leapfrogging: findings from the Korean industries. Research Policy 30, 459-483.

Lee, K., 2005. Making a technological catch-up: barriers and opportunities. Asian Journal of Technology Innovation 13 (2), 97-131.

Lee, K., Kim, Y.K., 2010. IPR and technological catch-up in Korea. In: Odagiri, H., Goto, A., Sunami, A., Nelson, R.R. (Eds.), Intellectual Property Rights, Development and Catch-up: an International Comparative Study. Oxford University Press, Oxford, pp. 133-167, chapter 5 .

Liu, J., Tylecote, A., 2009. Corporate governance and technological capability development: three case studies in the Chinese Auto industry. Industry and Innovation 16 (4-5), 525-544.

Lu, F., Feng, K.D., 2004. FaZhan WoGuo ZiZhu ZhiShiChanQuan QiCheGongYe de ZhengCe XuanZe (In Chinese: The Policy Choice in Developing China's Proprietary Passenger Car Industry). Beijing University Press, Beijing.

Malerba, F., Orsenigo, L., Peretto, P., 1997. Persistence in innovative activities, sectoral patterns of innovation and international technological specialisation. International Journal of Industrial Organisation 15, 801-826.

Mathews, J.A., 2002. Competitive advantages of the late-comer firm: a resourcebased account of industrial catch-up strategies. Asia Pacific Journal of Management 19, 467-488.

Motohashi, K., 2008. Licensing or not licensing? An empirical analysis of the strategic use of patents by Japanese firms. Research Policy 37 (9), 1548-1555.

Mowery, D.C., 2010. IPR and US economic catch-up. In: Odagiri, H., Goto, A., Sunami, A., Nelson, R.R. (Eds.), Intellectual Property Rights, Development and Catch-up: an International Comparative Study. Oxford University Press, Oxford, pp. 31-62, chapter 2 .

Neobard, B., 2009. Patents for ICT-type inventions in China. In: Presentation to the Asia-Pacific Technology Network, London, May.

OECD, 1996. Industrial Competitiveness Directorate for Science, Technology and Industry. OECD, Paris.

Odagiri, H., Goto, A., Sunami, A., 2010a. IPR and the catch-up process in Japan. In: Odagiri, H., Goto, A., Sunami, A., Nelson, R.R. (Eds.), Intellectual Property Rights, Development and Catch-up: an International Comparative Study. Oxford University Press, Oxford, pp. 95-132, chapter 4.

Odagiri, H., Goto, A., Sunami, A., Nelson, R.R., 2010b. Conclusion. In: Odagiri, H., Goto, A., Sunami, A., Nelson, R.R. (Eds.), Intellectual Property Rights, Development and Catch-up: an International Comparative Study. Oxford University Press, Oxford, pp. 412-430, chapter 13.

Schacht, W.H., 1997. Industrial Competitiveness and Technological Advancement: Debate Over Government Policy. Congressional Research Service, Washington, DC.

Sirmon, D.G., Hitt, M.A., 2003. Managing resources: linking unique resources, management and wealth creation in family firms. Entrepreneurship Theory and Practice 27 (4), 339-358.

Teece, D.J., 1998. Capturing value from knowledge assets: the new economy, markets for know-how, and intangible assets. California Management Review 40 (3), 55-79.

Tylecote, A., Liu, J., Cai, J., 2010. Why is mainland China rising in some sectors and failing in others? A critical view of the Chinese system of innovation. International Journal of Learning and Intellectual Capital 7 (2), 123-144.

Walmsley, T.L., Hertel, T.W., Ianchovichina, E., 2006. Assessing the impact of China's WTO accession investment. Pacific Economic Review 11 (3), 315-339.

Wu, H., Chiu, Y., Lee, T., 2010. IPR and catch-up: The case of Taiwan's IC industry. In: Odagiri, H., Goto, A., Sunami, A., Nelson, R.R. (Eds.), Intellectual Property Rights, Development and Catch-up: an International Comparative Study. Oxford University Press, Oxford, pp. 168-207, chapter 6.

Xia, D., Shi, D., Zhang, L., 2002. QiChe GongYe: JiShu JunBu Yu ChanYe ZuZhi (I Chinese, Automobile Industry: Technological Progress and Industrial Organisation). Shanghai University of Finance Economics Press, Shanghai. 
Xie, W., Wu, G., 2003. Differences between learning processes in small tigers and large dragons: Learning processes of two color TV firms within China. Research Policy 32, 1463-1479.

Xing, Y., 2011. China's High-tech Exports: Myth and Reality. GRIPS Discussion Paper No. 11-05. National Graduate Institute for Policy Studies, Tokyo, November.

Xing, Y., Detert, N., 2010. How iPhone Widens the US Trade Deficits with PRC. GRIPS Discussion Paper 10-21. National Graduate Institute for Policy Studies, Tokyo, November.
Xue, L., Liang, Z., 2010. Relationships between IPR and technology catch-up: some evidence from China. In: Odagiri, H., Goto, A., Sunami, A., Nelson, R.R. (Eds.), Intellectual Property Rights, Development and Catch-up: an International Comparative Study. Oxford University Press, Oxford, pp. 318-360, chapter 10.

Yin, R.K., 2003. Case Study Research: Design and Methods, 3rd ed. Sage, London.

Yin, R.K., 2008. Case Study Research: Design and Methods, 4th ed. Sage, London.

Zhang, J., 1999. May history remember them: a memoir of the Chinese Academy of Sciences and the 'Two bombs, one satellite' programme (in Chinese, Qing LiShi JiZhu TaMen - ZhongGuo KeXuYuan Yu 'LiangDanYiXing). People’s Daily, 6 May. 